\title{
The Effect of Microwaves on the Survivability of Brucella Microorganisms in Infected Cattle Milk
}

\author{
Mahmoud Essam Rashad Hamdy* and Nadia Abdel Azeim Shalaby \\ Department of Brucellosis, Animal Health Research Institute (AHRI) Dokki, Egypt
}

Submission: January 14, 2020; Published: January 29, 2020

*Corresponding author: Mahmoud Essam Rashad Hamdy, Department of Brucellosis, Animal Health Research Institute (AHRI) Dokki, Egypt

Abstract

This study was carried out to investigate the effect of microwave radiation on the viability of Brucella melitensis in contaminated cattle milk through establishing a correlation between milk volumes, microwave exposure time, measured Celsius temperature and viable counts of B. melitensis in inoculated milk. Microwave appliances were used in houses and many food stores in Egyptand worldwide, for warming milk that processed for human consumption. Microwave heating was performed using a household electronic microwave oven (Kenwood MW 579, a frequency of 2,450 MHz, and power of $900 \mathrm{~W})$. Brucella-free milk is inoculated with B. melitensis in a dose of $\left(1.3 \mathrm{X} 10^{8} \mathrm{CFU} / \mathrm{ml}\right)$ and samples are divided into $100 \mathrm{ml}$ and $200 \mathrm{ml}$ volumes and maintained at room temperature $\left(22^{\circ} \mathrm{C} \pm 3^{\circ} \mathrm{C}\right)$ or refrigeration temperature $\left(5{ }^{\circ} \mathrm{C} \pm 2{ }^{\circ} \mathrm{C}\right)$ prior to microwave exposure. Microwave radiations with full power $(\mathrm{P}=100)$ eliminate B. melitensis in $100 \mathrm{ml}$ milk samples kept at room temperature for 80 seconds with measured temperature reached $\left(82^{\circ} \mathrm{C}\right)$ and eliminated Brucellae in $200 \mathrm{ml}$ milk samples in 100 seconds with measured temperature of $\left(78^{\circ} \mathrm{C}\right)$. While in $100 \mathrm{ml}$ refrigerated milk kept at $\left(5^{\circ} \mathrm{C} \pm 2\right)$ that exposed to $30 \%$ of the microwave`s power $(\mathrm{P}=30)$ Brucella organisms still viable till 5 minutes and the organisms inactivated at 6 minutes with the measured temperature reached $\left(75^{\circ} \mathrm{C}\right)$. It was found that the warming program of the microwave either in $120 \mathrm{ml}$ inoculated milk for 1 minute or $240 \mathrm{ml}$ milk samples for 2 minutes, Brucella organisms are still viable at counts of $\left(7.1 \times 10^{4}\right.$ and $\left.8.3 \times 10^{3} \mathrm{CFU} / \mathrm{ml}\right)$, respectively and considered as a potential source of human infection. In conclusion, the warming microwave program is proved to be unfit to eliminate $B$. melitensis from contaminated cattle milk.

Keywords: Brucella melitensis; Viability; Microwaves; Milk

\section{Introduction}

Brucellosis is a classical zoonosis of worldwide public health and economic importance. Infected animals are the main sources of human infection. The disease frequently transmitted to man by direct or indirect contact with infected animals or their products. Brucellosis infects people of all age groups and of both sexes [1]. Although there have been great efforts exerted in controlling the disease in many countries, there still remain regions where the infection persists in domestic animals and human populations. There are only a few countries in the world that are officially declared free of the disease although they still have human brucellosis due to returning citizens from endemic countries [1].

Milk is a palatable highly nutritious fluid and many people have the custom of drinking milk or add it to their beverages or food. The global per capita dairy consumption of cattle milk was recently estimated in 2015 to be $111.3 \mathrm{~kg}$ per year. It was also estimated that the consumption of milk in developing countries is expected to increase in the coming years [2]. Milk produced from infected cattle, sheep, goats and camels, is frequently contaminated with Brucella pathogens and is considered a potential hazard as it contains large numbers of organisms. Tourists or business travelers to endemic areas may acquire brucellosis, usually by consumption of un-heat-treated milk, when visiting countries with known status of animal Brucellosis. Many heat treatment procedures including pasteurization and sterilization were employed for inactivation of pathogenic bacteria and rendering milk fit for human consumption. However, these thermal procedures have got some limitations by way of partial destruction of heat labile nutrients that affects the quality of milk, and sensory attributes [3].

Microwaves are described as they are electromagnetic radio waves that are within a frequency band ranged between $300 \mathrm{MHz}$ to $300 \mathrm{GHz}$. Microwave heating refers to dielectric heating due to polarization effects at a selected frequency band in a nonconductor. Microwave heating in food beverages occurs due to coupling of 
electrical energy from an electromagnetic field in a microwave cavity with the food and its subsequent dissipation within food product. This results in a sharp increase in temperature within the product. Microwave heating of milk has advantages over other conventional heat treatments due to its rapid increase in temperature, short time duration and it overcome the limitation imposed by the slow thermal diffusion process of conventional heating [4].

The application of microwave heating to pasteurize milk has been well studied and has been a commercial practice for quite a long time. The success of microwave heating of milk is based on established conditions that provide the desired degree of safety with minimum product quality degradation. Since the first reported study on the use of a microwave system for pasteurization of milk [5], several studies on microwave heating of milk have been carried out. The majority of these microwave-based studies have been used to investigate the possibility of shelf-life enhancement of pasteurized milk, application of microwave energy to inactivate milk pathogens, assess the influence on the milk nutrients or the non-uniform temperature distribution during the microwave treatment [6]. The application of microwave energy in bovine milk proved to inactivate Streptococcus faecalis, Yersinia enterocolitica, Campylobacter jejuni, and Listeria monocytogenes [7]. Up to the available literature, the effect of microwaves on the viability of Brucella microorganisms in milk was not yet studied. The aim of this study is to investigate the effect of the microwave radiation on the viability of Brucella melitensis in cow milk through establishing a correlation between milk volumes, exposure time and viable count of Brucella in milk, in a trial to check the efficiency of microwave to render Brucella infected milk safe for human consumption.

\section{Material and Methods}

\section{Preparation of Brucella strain}

Brucella melitensis was selected to run the current experiment on the basis that this strain is the common Brucella strain isolated from animals and man in Egypt and most Mediterranean countries [8]. The local strain was isolated from stomach contents of aborted ewe foetus. The organism was subjected to culture identification methods using; monospecific serum (A \& M), lysis by Tiblizi and IZ Brucella phages and growth on thionin and basic fuchsine dyes. All biotyping methods were done parallel with and in comparison, with Brucella melitensis reference strain (Ether strain) obtained from NVSL, DBL, USDA. The pure Brucella strain was incubated at $37 \mathrm{oC}$ for $72 \mathrm{~h}$ in tryptose soy agar (TSA) medium (Oxide). The experiment was performed in various times, fixed initial bacterial concentration and different Watts power $(300 \mathrm{w}$ and full power $900 \mathrm{w}$ ) to determine the effect of microwave radiation on viable Brucella organisms using viable colony counting methods.

\section{Inoculation of Milk}

Cow milk was aseptically obtained from Brucella free dairy herd, cooled at $4{ }^{\circ} \mathrm{C}$ and sent to the lab as soon as possible. Milk was inoculated with fresh Brucella culture using a loopful of culture suspended in $9 \mathrm{ml}$ of $0.85 \%(\mathrm{w} / \mathrm{v})$ sterile saline solution and final density was adjusted to MacFarland 0.5 . The final concentrations of the organisms were estimated through viable bacterial count of the inoculated milk.

\section{Microwave Heating}

Microwave heating was performed using household electronic microwave oven (Kenwood MW 579, a frequency of 2,450 MHz, and power of $900 \mathrm{~W}$ ). Inoculated milk divided into $100 \mathrm{ml}$ and $200 \mathrm{ml}$ volumes and maintained at room temperature $(22 \mathrm{C} \pm$ 3C). Microwave was used at high power for heating the inoculated milk. To study the effect of warming temperature on the viability of Brucella in milk, a warming program were applied, using another volumes of $120 \mathrm{ml}$ and $240 \mathrm{ml}$ of inoculated milk were microwaved for $60 \mathrm{sec}$ and $120 \mathrm{sec}$, respectively; according to the warming program listed in the instruction manual of the manufacture company. Just after microwave radiation, the temperature of the inoculated milk was taken using certified calibrated thermometer (ISO 9001). Inoculated milk was kept on bench till reach room temperature $\left(22{ }^{\circ} \mathrm{C} \pm 4^{\circ} \mathrm{C}\right)$. One hundred microliter of each treated milk were cultured on 3 plates of Brucella agar media. The experiment was carried out in triplicate and the mean of the standard error was calculated.

\section{Determination of viable count}

The milk subjected to the analysis was obtained from Brucellafree cattle farm. The whole amount of milk was inoculated with Brucella culture with the final bacterial dilution done by viable count is $1.3 \times 10^{8} \mathrm{CFU} / \mathrm{ml}$ milk [9]. Inoculated milk was divided into $100 \mathrm{ml}, 200, \mathrm{ml}, 120 \mathrm{ml}$ and $240 \mathrm{ml}$, whereas, these aliquots were kept at room temperature $22{ }^{\circ} \mathrm{C} \pm 2{ }^{\circ} \mathrm{C}$. Milk samples were put in the middle of the microwave instrument in unclosed vessels and exposed to the full power of the microwave (100: P) for the following periods of time:

a) t0 - milk samples not treated with microwaves, t10 milk samples treated for 10 seconds,

b) t20 - milk samples treated for 20 seconds, t30 - milk samples treated for 30 seconds,

c) $\mathrm{t} 40$ - milk samples treated for 40 seconds, t50 - milk samples treated for 50 seconds,

d) t60 - milk samples treated for 60 seconds, t70 - milk samples treated for 70 seconds,

e) $\quad$ t80 - milk samples treated for 80 seconds, t90 - milk samples treated for 90 seconds,

f) t100 - milk samples treated for 100 seconds, t110 - milk samples treated for 110 seconds, and t120 - milk samples treated for 120 seconds with microwave radiations.

To cover the effect of environmental conditions for keeping milk in the routine daily life, and to investigate the role of 
microwave effect on Brucella organisms in milk regardless of the effect of generated heat, another $100 \mathrm{ml}$ of milk samples kept in refrigerator at $5 \stackrel{\circ}{\circ} \mathrm{C} \pm 2 \stackrel{\circ}{\circ} \mathrm{C}$ were exposed directly to microwave radiations. These refrigerated milk samples were exposed to $30 \%$ of the microwave full power (P: 30 ) and for longer periods of time, namely, 0 -minute, $1 \mathrm{~min}, 2 \mathrm{~min}, 3 \mathrm{~min}, 4 \mathrm{~min}, 5 \mathrm{~min}, 6 \mathrm{~min}, 7 \mathrm{~min}$, and 8 minutes, respectively.

\section{Statistical Analysis}

Average results of the culture bacterial count (CFU) and $\log _{10}$ of the bacterial count were calculated using Microsoft Excel (2013). While significance of the obtained results was processed using simple one-way ANOVA. All analyses were done using SPSS 20.

\section{Discussion}

In Egypt, brucellosis is still an important public health hazard due to the consumption of unheat-treated milk or dairy products produced from unpasteurized milk that could be harboring viable Brucella organisms. Although, there are many methods to eliminate Brucellae in infected milk based mostly on heat treatment, namely; pasteurization, ultra-heat treatment, and boiling, nevertheless; all these methods are of high cost and time consuming, besides; the thermal impact on damaging milk constituents. Lowering the $\mathrm{pH}$ of the milk to an acidic level is also used to preserve milk. However, it was found that $\mathrm{B}$. abortus at a concentration of $10^{5} \mathrm{CFU} / \mathrm{ml}$ resists acidity of refrigerated milk at a $\mathrm{pH}$ of 4.0 and survive for up to 10 days of storage at $4^{\circ} \mathrm{C}[10]$.

Microwaves radiations are electromagnetic, non-ionizing waves with frequencies between 0.3 and $300 \mathrm{GHz}$ [11]. Microwave radiation is applied on different food products through different studies to inhibit some pathogenic bacteria including, E. coli, B. subtilis [12], salmonella [13], milk flora [14], inactivate Streptococcus faecalis, Yersinia enterocolitica, Campylobacter jejuni, and Listeria monocytogenes [7]. It is evident, from the obtained data that the increase in the exposure time of inoculated milk samples to microwave radiations is directly proportional with a measured temperature (Tables $1 \& 2$ ) and (Figures $1 \& 2$ ). The same observation can be applied on exposed milk to microwave radiations regardless of the milk volume (either $100 \mathrm{ml}$ or 200 $\mathrm{ml}$ ) or to initial milk temperature (milk kept in room temperature or refrigeration environment). It is also clear that the measured temperature of low milk volume $(100 \mathrm{ml})$ exposed to microwave radiation is higher than the measured temperature of the $(200 \mathrm{ml})$ volume.

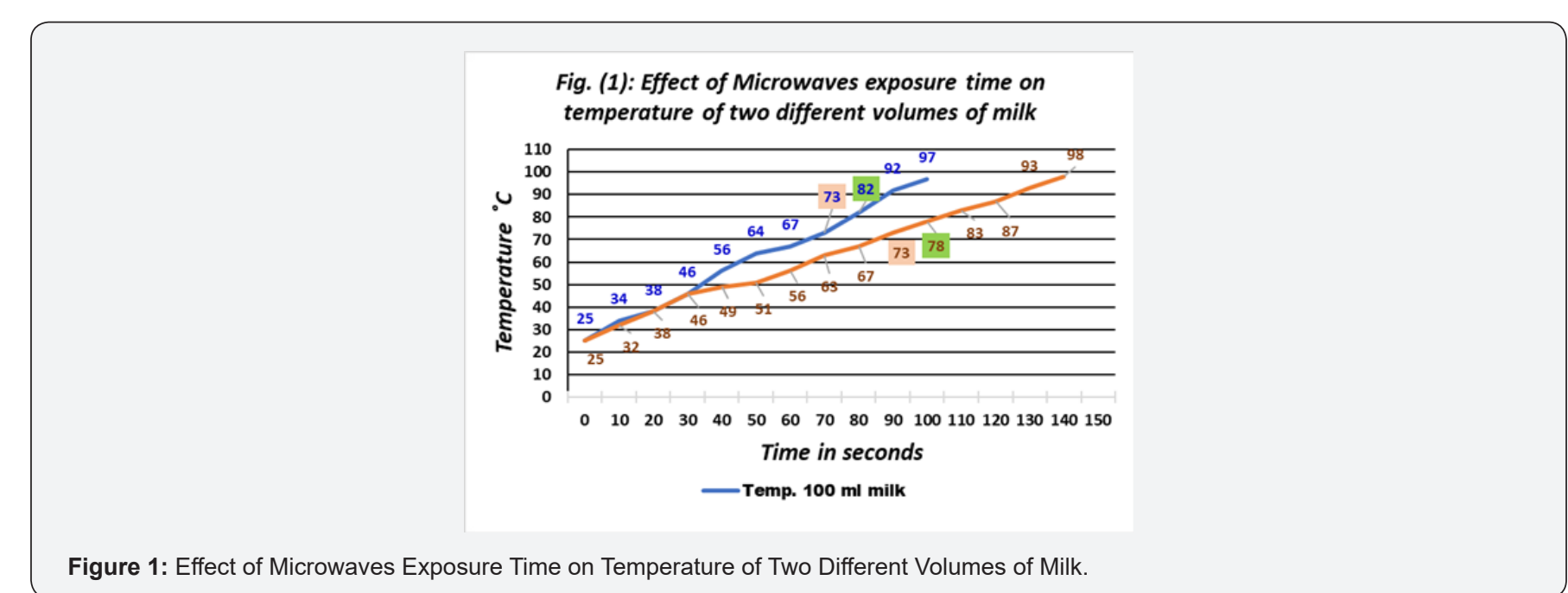

Figure 1: Effect of Microwaves Exposure Time on Temperature of Two Different Volumes of Milk.

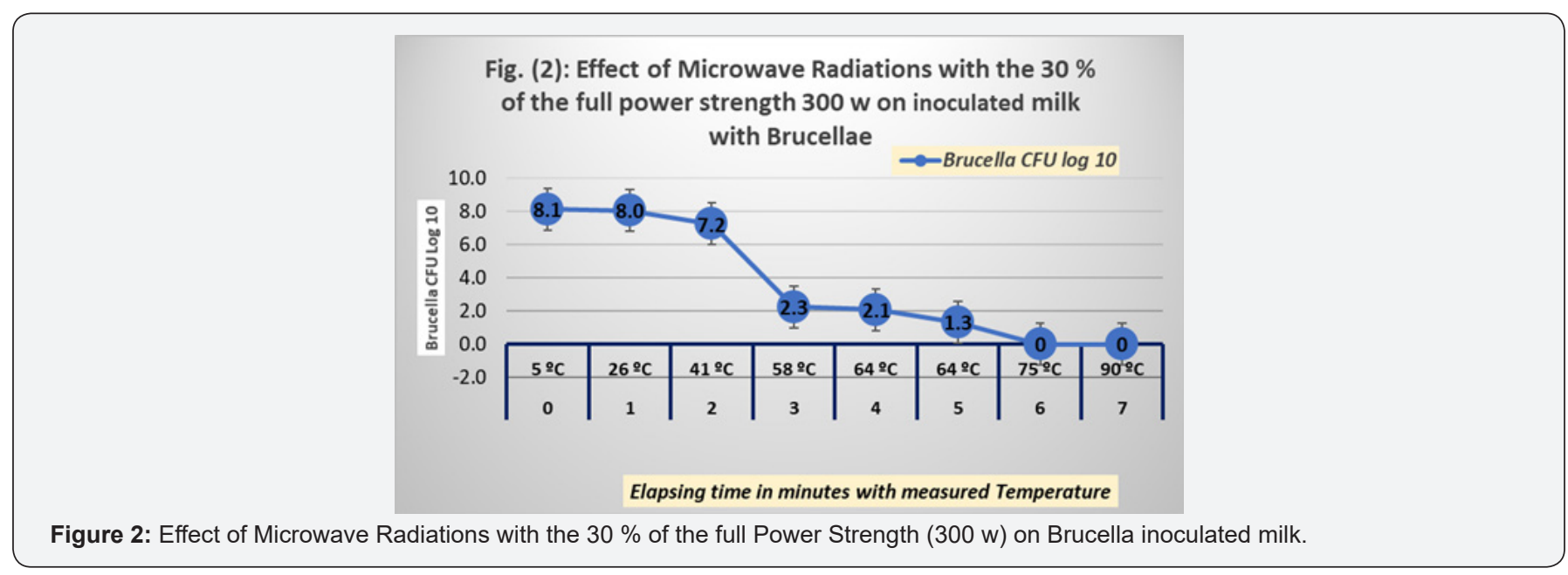




\section{Journal of Dairy \& Veterinary Sciences}

Table 1: Effect of Microwaves and Exposure Time on Viability of Brucellae on $100 \& 200 \mathrm{ml}$ of Brucella inoculated milk kept at room temperature.

\begin{tabular}{|c|c|c|c|c|c|}
\hline \multirow{2}{*}{ Serial } & \multirow{2}{*}{ Time (Sec.) } & \multicolumn{2}{|c|}{100 Milk Samples } & \multicolumn{2}{|c|}{200 Milk Samples } \\
\hline & & Tempe. & B. CFU/ml in Milk & Tempe. & B. $\mathrm{CFU} / \mathrm{ml}$ in Milk \\
\hline 1 & 0 & $25^{\circ} \mathrm{C}$ & $1.3 \times 10^{8}$ & $25^{\circ} \mathrm{C}$ & $1.3 \times 10^{8}$ \\
\hline 2 & 10 & $34^{\circ} \mathrm{C}$ & $6.5 \times 10^{7}$ & $32^{\circ} \mathrm{C}$ & $8.6 \times 10^{7}$ \\
\hline 3 & 20 & $38^{\circ} \mathrm{C}$ & $3.3 \times 10^{6}$ & $38^{\circ} \mathrm{C}$ & $5.1 \times 10^{6}$ \\
\hline 4 & 30 & $46^{\circ} \mathrm{C}$ & $2.1 \times 10^{5}$ & $46^{\circ} \mathrm{C}$ & $2.7 \times 10^{5}$ \\
\hline 5 & 40 & $56^{\circ} \mathrm{C}$ & $3.8 \times 10^{4}$ & $49^{\circ} \mathrm{C}$ & $8.7 \times 10^{4}$ \\
\hline 6 & 50 & $64^{\circ} \mathrm{C}$ & $3.9 \times 10^{3}$ & $51^{\circ} \mathrm{C}$ & $1.2 \times 10^{4}$ \\
\hline 7 & 60 & $67^{\circ} \mathrm{C}$ & $7.6 \times 10^{2}$ & $56^{\circ} \mathrm{C}$ & $1.1 \times 10^{3}$ \\
\hline 8 & 70 & $73^{\circ} \mathrm{C}$ & $1.3 \times 10^{2}$ & $63^{\circ} \mathrm{C}$ & $4.5 \times 10^{2}$ \\
\hline 9 & 80 & $82^{\circ} \mathrm{C}$ & No growth & $67^{\circ} \mathrm{C}$ & $1.1 \times 10^{2}$ \\
\hline 10 & 90 & $92^{\circ} \mathrm{C}$ & No growth & $73^{\circ} \mathrm{C}$ & $0.8 \times 10^{1}$ \\
\hline 11 & 100 & $97^{\circ} \mathrm{C}$ & No growth & $78^{\circ} \mathrm{C}$ & No growth \\
\hline $120 \mathrm{ml}^{*}$ & 60 & $\mathrm{P}=\mathrm{A}$ & Brucella Growth & $54^{\circ} \mathrm{C}$ & $7.1 \times 10^{4}$ \\
\hline $240 \mathrm{ml}$ & 120 & $\mathrm{P}=\mathrm{A}$ & Brucella Growth & $56^{\circ} \mathrm{C}$ & $8.3 \times 10^{3}$ \\
\hline
\end{tabular}

Table 2:

\begin{tabular}{|c|c|c|c|}
\hline Se. & Time & Temperature & CFU of Brucella/ml \\
\hline 1 & 0 Time & $4-6^{\circ} \mathrm{C}$ & $1.3 \times 10^{8}$ \\
\hline 2 & 1 minutes & $26^{\circ} \mathrm{C}$ & $1.1 \times 10^{8}$ \\
\hline 3 & 2 min. & $41^{\circ} \mathrm{C}$ & $1.7 \times 10^{7}$ \\
\hline 4 & 3 min & $58^{\circ} \mathrm{C}$ & $1.8 \times 10^{2}$ \\
\hline 5 & 4 min. & $64^{\circ} \mathrm{C}$ & $1.2 \times 10^{2}$ \\
\hline 6 & 5 min. & $64^{\circ} \mathrm{C}$ & $0.3 \times 10^{2}$ \\
\hline 7 & 6 min. & $75^{\circ} \mathrm{C}$ & 0 (negative culture) \\
\hline 8 & 7 min. & $90^{\circ} \mathrm{C}$ & 0 (negative culture) \\
\hline 9 & 8 min. & - & 0 (negative culture) \\
\hline 10 & 9 min. & - & 0 (negative culture) \\
\hline
\end{tabular}

*Start Temperature $5^{\circ} \mathrm{C} \pm 2^{\circ} \mathrm{C}$ (Refrigerated Milk) using $30 \%$ of Microwave power $(\mathrm{P}=30)$.

For milk samples keptatroom temperature, Brucella organisms still survive in $100 \mathrm{ml}$ milk samples exposed to $900 \mathrm{w}$ full power of the microwave $(\mathrm{P}=100)$ for up to 70 seconds and the measured temperature at that time was $73 \stackrel{\circ}{\circ} \mathrm{C}$. But no viable Brucella organisms could be isolated at $80 \mathrm{sec}$ with measured temperature of $82{ }^{\circ} \mathrm{C}$. On the other hand, Brucellae still present live in $200 \mathrm{ml}$ milk samples for up to 90 seconds and the measured temperature at that time was $73 \stackrel{\circ}{\circ}$. But no viable Brucella organisms could be isolated at $100 \mathrm{sec}$ with measured temperature of $78{ }^{\circ} \mathrm{C}$ (Table 1 ).

While in milk samples kept at refrigeration temperature (5 C $\left.\pm 2{ }^{\circ} \mathrm{C}\right)$, milk contaminated with Brucella melitensis exposed to 30 $\%$ of the full power of the microwave ( $\mathrm{P}=30)$, Brucellae was found viable for up to 5 minutes $(300 \mathrm{sec})$ with the measured temperature of $64{ }^{\circ} \mathrm{C}$, but not viable at 6 minutes $(360 \mathrm{sec})$ with a measured temperature of $\left(75^{\circ} \mathrm{C}\right)$. This observation may be attributed to the fact that the thermal effects of microwave treatment are related to the heat generated following the absorption of their energy by water, organic molecules or ions [15]. Food heating by microwave is the results of the conversion of microwave energy into heat by the friction of dipole molecules vibrating due to rapid fluctuation in the electromagnetic field [16].

Exposure of milk to microwave radiation directed to a molecular level through the molecular interaction with the electromagnetic field, precisely, through molecular friction resulting from dipole movements of polar solvents and from the conductive migration of dissolved ions. Water in milk is the primary dipolar component responsible for the dielectric heating. In an alternating current electric field, the polarity of the field is varied at the rate of microwave frequency and molecules attempt to align themselves with the changing field. As a result, thermal effect is produced as a result of internal molecular friction. In addition, microwave radiations generate heating through the polarization of ions as a 
result the movement of the ionic molecules [17].

It is noteworthy to mention that the warming beverage microwave program (A - 6) failed to decontaminate Brucella organisms in tested milk volumes of $(120 \mathrm{ml}$ or $240 \mathrm{ml})$, regardless to the time of the exposure (1 $\mathrm{min}$ or $2 \mathrm{~min}$ ). From the obtained results, it is evident that milk contaminated with Brucellae is unsafe for consumers in warm exposure program of the microwave. In this study, it was found that Brucella microorganisms in milk exterminated when exposed to microwave radiations with a measured temperature of $82{ }^{\circ} \mathrm{C}$ of the volume of $100 \mathrm{ml}$ for about 80 seconds and $78^{\circ} \mathrm{C}$ of the $200 \mathrm{ml}$ volume for 100 seconds (Table 1). While it was proved by many authors that Brucella organisms when subjected to heat, the organism disintegrated at $63^{\circ} \mathrm{C}$ for 30 minutes [9].

Based on this results, it is evident that Brucella microorganisms eliminated in milk exposed to microwave radiations not from thermal effect alone, as; the measured temperature for this short time (80 sec and $100 \mathrm{sec}$ in $100 \mathrm{ml}$ and $200 \mathrm{ml}$ of milk) can not alone e responsible for deactivation of Brucellae in milk. Our findings substantiate the conclusions of many authors that microwave radiations alone has a decontamination effect on the bacterial organisms regardless of the thermal effect. It was found that microwaves found that microwaves at $835 \mathrm{MHz}$ showed a resonant- like effect on the growth of some yeasts, including Saccharomyces cerevisiae, which was not dependent on the amount of absorbed energy from the microwaves [18]. The growth was interchangeably enhanced or decreased at steps of $10 \mathrm{MHz}$ within the frequency range studied. In another study in which Escherichia coli cultures were exposed to microwaves $(18 \mathrm{GHz}$, absorbed power $1500 \mathrm{~kW} / \mathrm{m} 2$, electric field $300 \mathrm{~V} / \mathrm{m}$ ) at temperatures below $40^{\circ} \mathrm{C}$ (to avoid the thermal effects of microwaves), transient morphological changes (dehydrated appearance) and openings of pores in the cell membrane (approximately $20 \mathrm{~nm}$ in diameter, enabling passage of dextran molecules) were observed [19].

It seems that this effect is electro kinetic in nature (caused by increased movements of anions and cations), causing localized structural disarrangements of the cell membrane, which results in the emergence of pores. Large membrane pores cause leakage of vital intracellular molecules out of the bacterial cells, which may lead to their death. The effect was reversible because more than $87 \%$ of exposed cells remained viable. Regardless to the effect of the microwave radiations on the cell membranes, microwaves generate non-thermal effect that enhances enzymatic reactions in bacterial cells, such as non-aqueous esterification (formation of ester-type of chemical compounds without participation of water), and this effect is substrate concentration-dependent [20, 21].

Up to our knowledge, there is no available literature investigated the effect of microwave radiation on Brucella organisms in milk. However, it was found that wild E. coli and Bacillus subtilis organisms radiated with microwave at the power of $600 \mathrm{MHz}$ at $70{ }^{\circ} \mathrm{C}$ led to inactivation of both organisms and $B$. subtilis did not show any t lysing or destructing cell wall while $E$. coli showed destruction [20]. Exposure of food including milk to microwave radiation is a relatively new procedure in this study we investigated its impact on the viability of viable Brucella organisms in milk. In view of this experiment it could be concluded that microwave radiation with full power $(\mathrm{P}=100)$ and frequency of $2,450 \mathrm{MHz}$, and power of $900 \mathrm{~W}$, eliminate Brucellae $\left(1.3\right.$ X $10^{8} \mathrm{CFU}$ of / $\mathrm{ml}$ ) in $100 \mathrm{ml}$ milk kept in room temperature in 80 seconds in $200 \mathrm{ml}$ milk samples in 100 seconds. While in refrigerated milk (5 ${ }^{\circ} \mathrm{C} \pm 2$ ) exposed to $1 / 3$ of the microwave power $(\mathrm{P}=30)$ Brucella organism still viable till 5 minutes and the organisms killed at 6 minutes. It is noteworthy to mention that the warming program of beverage in the microwave either in heating $120 \mathrm{ml}$ milk for 1 minute or $240 \mathrm{ml}$ milk samples for 2 minutes, the organism is still viable. Microwave radiations can be a tool for keeping milk safe for consumption but with the exposure time followed in this study and taking into consideration milk kept in room temperature or refrigerating temperature.

\section{References}

1. World Health Organization (2006) Brucellosis in humans and animals, Produced by the World Health Organization in collaboration with the FAO, OIE \& WHO.

2. World Dairy Situation (2016) Bulletin of the International Dairy Federation 485/2016. The world dairy situation 2014-2016.

3. Ahmed J, Ramaswamy H (2014) Handbook of food preservation in: Rehman S (ed). Microwave Pasteurization and Sterilization of Foods, 2nd edn. CRC, London. pp. 691-713.

4. Sieber R, Eberhard P, Fuchs D, Gallmann PU, Strahm W (1996) Effect of microwave heating on vitamins A, E, B1, B2 and B6 in milk. J Dairy Res 63(1): 169-172.

5. Hamid MAK, Boulanger RJ, Tong SC, Gallop RA, Pereira RR (1969) Microwave pasteurization of raw milk. J. Microwave Power 4(4): 272275.

6. Koutchma T, Le Bail A, Ramaswamy HS (1998) Modeling of process lethality in continuous-flow microwave heating-cooling system, in Proc. Int. Microwave Power Institute, Chicago, p74-77.

7. Choi HK, Marth EH, Vasavada PC (1993) Use of microwave energy to inactivate Yersinia enterocolitica and Campylobacter jejuni in milk. Milchwissenschaft 48(3): 134-136.

8. Wareth G (2019) Brucellosis in the Mediterranean countries: history, prevalence, distribution, current situation and attempts at surveillance and control. OIE, Technical Series 12 .

9. Alton GG, Jones LM, Angus RD, Verger JM (1988) Techniques for the brucellosis laboratory. Institute National de la Recherché Agronomique, Paris, France.

10. Estrada AZ, Lydia MG, Mendoza, Miroslava S, López EMS, et al. (2005) Survival of Brucella abortus in milk fermented with a yoghurt starter culture. Rev Latinoam Microbiol 47(3-4): 88-91.

11. Balbani AP, Montovani JC (2008) Mobile phones: influence on auditory and vestibular Systems. Braz J Otorhinolaryngol 74: 125-131.

12. Janković SM, Milorad ZM, Milan LJN (2014) The Effects of Microwave Radiation on Microbial Cultures. Hospital Pharmacology 1(2): 102108. 
13. Jamshidi A, Ghasemi A, Mohammadi A (2009) The effect of short-time microwave exposures on Salmonella typhimurium inoculated onto chicken drumettes. Iranian Journal of Veterinary Research, Shiraz University 10(4): 378-382.

14. Dumuta A, Ovidiu R, Liviu, Florin B, Liliana C (2010) Preliminary Researches Regarding the Microwaves influence on milk microflora. Analele Universităţii din Oradea-Fascicula Biologie Tom 17: 103-107.

15. Michaelson SM (1974) Effects of exposure to microwaves: problems and perspectives. Environ Health Perspect 8: 133-155.

16. Kowalski S, Lukasiewicz M, Bednarz S, Panuś M (2012) Diastase number changes during thermal and microwave processing of honey. Czech J. Food Sci 30(1): 21-26.

17. Oliveira MEC, Franca AS (2002) Microwave heating of food stuff. J Food Eng 53(4): 347-359.
18. Grundler W, Keilmann F, Putterlik V, Strube D (1982) Resonant-like dependence of yeast growth rate on microwave frequencies. $\mathrm{Br}$ J Cancer Suppl 5: 206-208.

19. Yury S, Alex T, Natasa MD, Rodney C, Russell JC, et al. (2011) Specific electromagnetic effects of microwave radiation on Escherichia coli. Appl Environ Microbiol 77(9): 3017-3023.

20. Woo IS, Rhee IK, Park HD (2000) Differential damage in bacterial cells by microwave radiation on the basis of cell wall structure. Appl Environ Microbiol 66(5): 2243-2247.

21. Wan HD, Sun SY, Hu XY, Xia YM (2012) Non-thermal effect of microwave irradiation in non-aqueous enzymatic esterification. Appl Biochem Biotechnol 166(6): 1454-1462.

\section{Your next submission with Juniper Publishers will reach you the below assets}

- Quality Editorial service

- Swift Peer Review

- Reprints availability

- E-prints Service

- Manuscript Podcast for convenient understanding

- Global attainment for your research

- Manuscript accessibility in different formats

( Pdf, E-pub, Full Text, Audio)

- Unceasing customer service

Track the below URL for one-step submission https://juniperpublishers.com/online-submission.php 